\title{
Toward an integration of behavioural and cognitive psychologies through instructional technology (1)
}

\author{
Wesley C. Becker \\ University of Oregon
}

\begin{abstract}
The schism between operant behavioural and cognitive psychological views is examined with the aim of showing the potentials for their convergence when an instructional perspective is taken. As Lee (1988) points out, part of the problem lies in operant psychologists' use of stimulus-response language when they are really talking about condition-action sequences or means-to-ends. The inaccurate presentation of the operant position by cognitive psychologists is also part of the problem, and for the most part, neither reads the other's literature. With better communication, these problems could be overcome, although underlying philosophies of science might still differ.
\end{abstract} An overtised-operant view of instruction on cognitive processes provides a
further basis for closing the schism. Building from the behavioural
processes of discrimination learning, chaining, verbal learning, etc., more
complex cognitive structures can be described in terms of the more
elemental structures from which they are built. Engelmann and Carnine's
(1982) theory of instruction provides a key (through overt teaching
strategies) in bridging the gap between basic operant principles and higher
cognitive structures.

Operant psychology based interpretations of the changes that occur from being a novice to being an expert also are discussed to demonstrate additional commonalities between behavioural and cognitive positions.

Historically, instructional design grew out of research on behaviour change and the study of higher cognitive processes, such as concept learning and problem solving. In looking at this research, the first thing to impress one is the major schism between those professing an operant behavioural (or radical behavioural, if you prefer) approach, such as 
Skinner (1953, 1957, 1968, 1977), Keller (1968), and Goldiamond and Dyrud (1966), and those professing a cognitive information-processing approach, such as, Gagne and Briggs (1974, 1979), Glaser (1987), and J. R. Anderson (1990). There clearly are polarised "good guys" and "bad guys" here, and which-are-which depends on your bias.

\section{Contributions to the Behaviourist-Cognitivist conflict}

Part of the conflict between operant and cognitive psychologists is due to the operant psychologists' choice of the terms stimulus and response as the language to describe their fundamental concepts and principles (Lee, 1988). Another part of the conflict derives from the false or inaccurate teachings of what operant behaviour theory is by cognitive psychologists. For example, Anderson (1990) cites John Watson (1930) as his basic source on behaviourism. In Anderson's judgment, behavioural views led to the study of rat behaviour which had little relevance to cognitive psychology. "In retrospect, it is hard to understand how behaviourists could have taken an antimental stand and clung to it so long" (Anderson, 1990, p. 8). In Anderson's text on Cognitive Psychology, no reference is made to B. F. Skinner, even though Skinner had much to say about cognitive behaviour and is the most famous of the contemporary behaviour theorists (see Skinner, 1953, 1957, 1968). Anderson cites linguist Noam Chomsky's (1959) criticism of behavioural descriptions of verbal learning (page 10) without reference to Skinner's (1957) Verbal Behavior or MacCorquodale's (1969) often cited response to Chomsky's criticisms. It is common knowledge that operant behaviourist and cognitivists rarely cite (much less read) each other's work.

It is the thesis of this paper that the miscommunication between behaviourists and cognitivists need not exist when dealing with applications of psychology to instructional design, although it might go on forever when it comes to issues of a philosophy of science and research methods. I see three potential bases for improving communications and showing parallels in positions.

The first basis comes from the suggestion by Lee (1988) that operant psychologists give up their stimulus-response language and instead talk about means-to-reaching-ends-in-context. Instead of saying "The red light was a discriminative stimulus for a braking response, because in the past this response had been negatively reinforced by avoiding an accident (or ticket)," one might say "In the context of street intersection with heavy traffic, the braking action was a means of preventing an adverse consequence (end)." The language Lee proposes makes clear that operant psychology is concerned with human actions (operants) not with specific responses or specific acts. By use of such language, which is still technically correct within operant theory, the possibility of misinterpretation by cognitive psychologists is reduced. 
A second basis for integration is in the demonstration (contrary to the views of many cognitive psychologists) of how basic concepts and procedures from operant psychology can be shown to produce higher order cognitive processes. Engelmann and Carnine's (1982) Theory of Instruction is at the heart of this demonstration, as is Gagne's work (1968, 1977).

A third basis for integration can be found in an analysis from an operant psychology perspective of the cognitive psychologists' work on the differences between novices and experts. In developing this paper, these three bases for bringing integration of thinking, and perhaps understanding of viewpoints, will be expanded with the hope of opening up communications between opposing camps.

\section{The Language of Operant Psychology}

The basic concepts of operant psychology form a three-term contingency:

$$
\text { Stimulus ---> Response ---> Consequence }
$$

Consequences are often considered the major focus of operant paradigms and therefore will be discussed first. Consequences are defined by their functional effect on behaviour. Those that increase behaviour in the future under the given stimulus conditions are called reinforcers. Those that weaken behaviour are called punishers. It takes investigation to determine what, in fact, functions as an effective consequence. However, from knowledge of humans (ie, their similar genetic and learning histories) good guesses about what might serve as effective consequences are not too difficult to make.

Despite the common opinion that consequences are the primary (and to some "only") variable considered by operant psychologists, antecedent stimuli play a critical role in the learning actions that might be called intelligent. Preceding stimuli come to set the occasion for operant responses (i.e., cue them) because of the effects of prior consequences. When a particular class of responses are reinforced (and responses not in that class are not reinforced) in the presence of a class of stimuli (but not others), the procedure is called differential reinforcement. The preceding stimuli that come to function to cue particular actions are called discriminative stimuli (or $\mathrm{S}^{\mathrm{d}} \mathrm{S}$ ). The important point for cognitive psychologists to take note of is that through differential reinforcement $S^{\mathrm{d}} \mathrm{S}$ can become what is common to a set stimulus examples; that is they can be the essential features of concepts. For example, a variety of steering wheels can control common steering responses; or a range of red colours can control the verbal response "red." 
The operant response, by definition, is what has a common effect on the environment; that is, an operant response is described by the common effect of a class of responses. For example, in a Skinner box, it makes no difference whether a rat presses the lever with a front foot, a hind foot, or her nose. The lever-pressing action is defined by a common effect, depressing the lever 0.5 centimetre or so. For language conventions, the common effect is what teachers (or other social agents) will accept as correct. Thus, in every real sense operant psychology is describing a model for intelligent human behaviour, and the experimental work by operant psychologists on concept learning, prompting, chaining, shaping, problem solving, stimulus equivalence, the matching law, rule-governed behaviour, and so forth, have very real implications for instructional design. In other

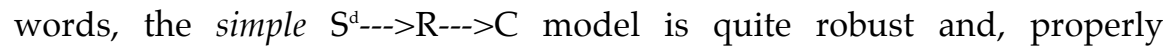
understood, can contribute to the understanding of lots of human learning usually restricted to domain of cognitive psychology. In view of all of this, Lee (1988) recommends that operant psychologists stop talking about discriminative stimuli and operant responses and talk about conditions, actions, and their contingent consequences. Actions are the means to certain ends under specified conditions - and this is how cognitive Psychologists talk about human action. The only real difference between operant and cognitive views is in the specification of causes. Cognitivists place causes in the mind, behaviourist place them in the environment and/or the learning history of the organism. The instructional designer must place the causes of learning where they are controllable by the teacher or teaching machine, ie, in the "environment" called the instructional program.

Instructional designers focus on teaching people when to do what. Consequences (feedback on correctness, corrections, praise, etc.) are still important, but are not emphasised in a discussion of design strategies.

Instead the focus is on the an $S^{d--->R}$ relationships (when to do what), which define the tasks which are the focus of instructional analysis. As such, $S^{d--->R}$ units can be seen as the basic building blocks (component tasks) in behavioural chains, in procedures, and in more complex forms, such as problem-solving routines and strategies. These building blocks also can be found in the production tables of artificial intelligence programs. For example, Newell, Shaw, and Simon's (1957) AI program called the General Problem Solver deals with route-to-goal problems. One class of problems deals with how to get from one place to another in the United States. A database of bus, train, and air routes is used, along with maps, a distance reduction rule, and a production table to help decide when to do what. The distance reduction rule is: "Set up subproblems that maximally reduce the uncovered distances." The production table takes this form: 


$\begin{array}{ll}\text { Condition }\left(S^{\mathrm{d}}\right) \text {---------> } & \text { Action }(\mathrm{R}) \\ \text { If over } 1000 \text { miles } & \text { Use a plane } \\ \text { If between } 101 \text { and } 1000 & \text { Use a train or bus } \\ \text { If between } 1 \text { and } 100 & \text { Use a car or taxi } \\ \text { If under } 1 \text { mile } & \text { Walk }\end{array}$

Newell, et al's basic artificial intelligence program was also effective in solving other route-to-goal problems with other databases and production tables. The important point here is recognition of the sameness of the concepts being used by cognitive and operant psychologists. By identifying these samenesses in route-to-goal problems, for example, strategies for teaching similar problem-solving procedures become apparent. For route-to-goal problems, problem solving requires learning how and when to reference databases (or fact systems, as they will be called later), how to discriminate relevant features of the problem that determine use of the procedure table, and how to apply the distance reduction rule in using the procedure table. (2)

\section{From the $\mathbf{S}^{\mathrm{d}}$--.-> R Paradigm to Problem Solving}

The theory of instruction developed by Siegfried Engelmann and Douglas Carnine (1982) provides some key analyses that help to bridge the gap from the $S^{d}--->R$ paradigm to higher cognitive processes, such as problem solving and cognitive schemes. Engelmann and Carnine's Theory of Instruction provides explicit strategies for teaching different kinds of cognitive knowledge. (See review by Brophy, 1984.) In the process of specifying the specific steps the teacher, instructor, or computer program should take to teach different kinds of knowledge efficiently, they have described what I would call a behavioural theory of cognitive instruction.

They begin with a macro-description of three kinds of analyses that are required to specify efficient conditions for the design of instruction for the teaching of cognitive skills - the analysis of behaviour, the analysis of knowledge, and the analysis of the communications used in teaching. These analyses are illustrated in Figure 1.

\section{The analysis of behaviour}

The analysis of behaviour is concerned with what we have learned from operant psychology about efficient teaching. In terms of applications, this knowledge is best summarised as what is common to mastery learning models (Becker, 1986). Mastery learning models set the constraints for teaching any task and for efficient use of teaching time. As should be apparent from Table 1, the models have much in common with systemsanalysis models for the design of instruction as illustrated in the work of Gagne and Briggs (1979). 


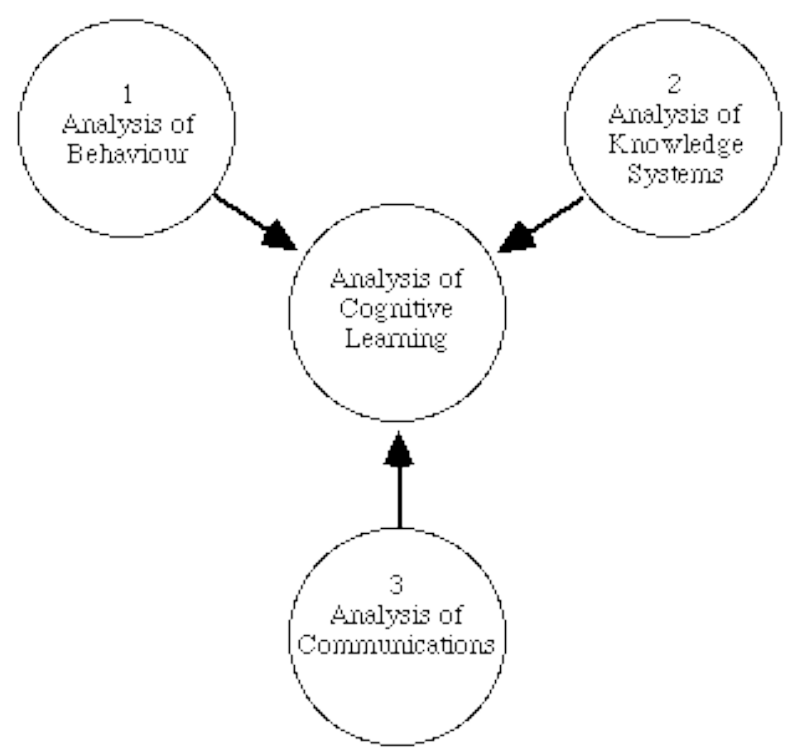

Figure 1: Three analyses necessary for the design of cognitive learning structures. (Reproduced with permission of the authors from Engelmann and Carnine (1982) Theory of Instruction. Copyrighted 1982 by S. E. Engelmann.)

Table 1: Nine features of mastery learning models. Steps to take before, during, and after instruction

\begin{tabular}{|c|c|c|}
\hline Before Instruction --> & During Instruction --> & After Instruction \\
\hline $\begin{array}{l}\text { 1. Specify objectives } \\
\text { 2. Test preskills }\end{array}$ & $\begin{array}{l}\text { 3. Motiwate - engage in } \\
\text { active leaming. } \\
\text { 4. Develop "quality } \\
\text { instnuction" } \\
\text { 5. Allow differential } \\
\text { time to mastery. } \\
\text { 7. Conect and reteach } \\
\text { when needed. } \\
\text { 8. Give adequate practice } \\
\text { to mastery. }\end{array}$ & $\begin{array}{l}\text { 6. Test subunits } \\
\text { often. Give } \\
\text { feedback often } \\
\text { (ungraded) }\end{array}$ \\
\hline & & $\begin{array}{l}\text { 9. Test for long-tem } \\
\text { mastery. }\end{array}$ \\
\hline
\end{tabular}

\section{The analysis of cognitive knowledge forms}

Engelmann's analysis of Cognitive Knowledge Forms is illustrated in Table 2. This analysis has much in common with Gagne's $(1968,1977)$ hierarchical structure of knowledge. Gagne's analysis begins with simple 
discriminations, which are prerequisites for learning concrete concepts (from examples), which are prerequisites for learning rules and ruledefined concepts, which are prerequisites for learning higher-order rules (problem-solving strategies). The two analyses differ in several important details. For example, Gagne does not discriminate among types of basic concepts that can be taught with different strategies. He does not separate empirical "rules" (generalisable facts) from logical rules (transformation rules), and Gagne omits fact systems and problem-solving routines (algorithms). Gagne does discuss problem solving strategies, which Engelmann omits from his analysis. Problem solving strategies should be added to Engelmann's scheme a continuing goal for analysis. Problemsolving strategies present many problems for instruction because strategies tend to be domain specific and require domain-specific databases of facts, concepts, rules, and principles.

Table 2: Engelmann and Carnine's (1982) taxonomy of cognitive knowledge forms

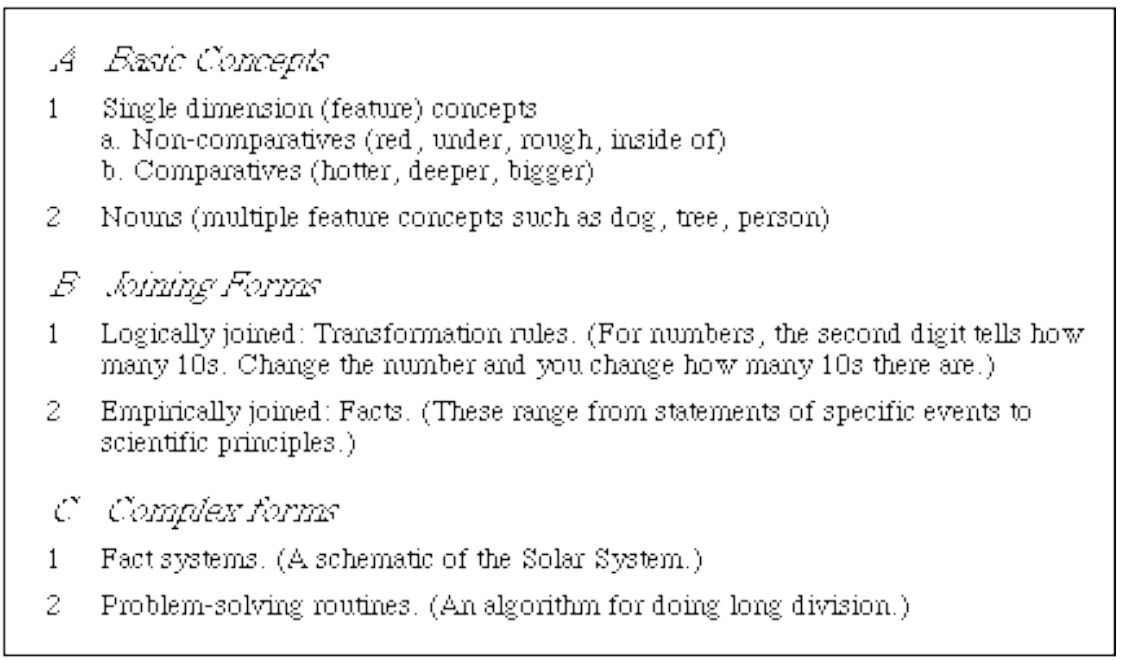

The goals in the analysis of cognitive knowledge forms are two fold. The first goal is to identify types of knowledge forms (eg, concepts, rules) that can be taught with a common strategy. Some design strategies will be illustrate later. The identification of successful strategies for different types of knowledge provides the basis for a theory of instruction, ie, given a type of knowledge, a given design strategy is provided by the theory. The second goal is to find samenesses across pieces of knowledge that provide the basis for general-case instruction (Becker, 1986). These samenesses provide the basis for concepts, logical rules, empirical principles, and problem-solving routines. Success with this goal contributes to efficient instruction in that a basis for teaching generalisations is provided. Bruner 
(1966) called this goal of knowledge analysis economy of representation, and used the example of the logical rule called the Pythagorean theorem. This rule summarises properties common to all right triangles.

In general-case learning, one can teach through some examples, and the student can do any of the possible class members if the proper examples have been chosen. Non-general-case learning involves specific facts ("The yellow pencil is on the table") and fact systems (eg, a mapping of geological eras by the depth of layers found in a river gorge).

To better understand the hierarchical structure in Table 2, consider the problem-solving routine for fractions presented in Figure 2. Examine it and identify the rules and concepts that should be taught (component skills) before the full routine is presented.

Task: Make a picture of this fraction and tell me what it equals

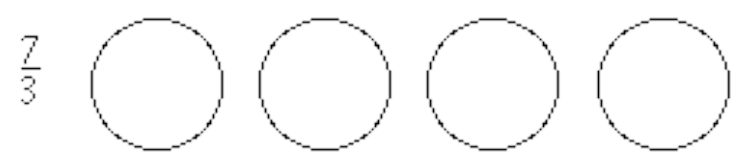

1. How many parts in each whole? Jhus
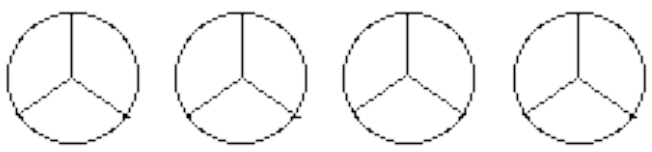

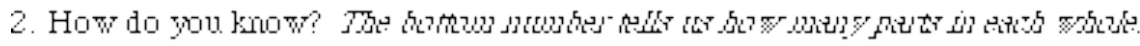

3. Make the pants in each whole.

4. How many parts do we have? siuss

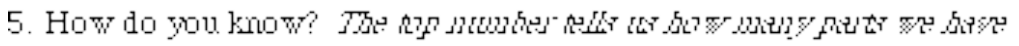

6. Fill in the parts we have.
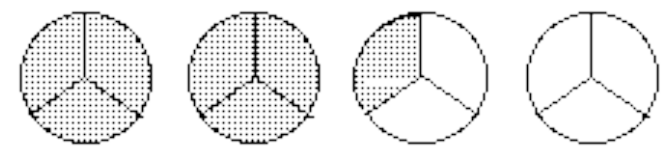

7. So what does the fraction equal? a J/A whoch

Figure 2: A routine for picturing a faction. Teacher wording is in lower case letters, expected student response is in capital letters. The circles are the wholes to be divided into parts and filled in. 
The two transformation rules ("The bottom number tells us how many parts in each whole" and "The top number tells us how many parts we have") are joining forms (statements formed by joining together two or more concepts). The concepts that might have to be taught beforehand include (among others) fraction, equal, parts, and whole. Note that generalisable procedures can be derived from transformation rules and principles. For example, for the rule, "The bottom number tells us how many parts in each whole," the procedure is "Make as many parts in each whole as the bottom number tells you." For the principle, "If you heat matter, it expands," the procedure is, "To expand matter, heat it." Problemsolving routines involve sets of concepts, rules, and principles, and the procedures derived from them. From an operant psychology perspective, these activities involve primarily discrimination learning (concepts and rules), verbal response learning, and at times other motor operations under the control of verbal cues (eg, making lines to represent a number, counting from-a-number-to-a-number, writing answers).(3)

\section{Analysis of communications}

Engelmann and Carnine analyse various types of knowledge to determine sequencing strategies. The goal is to find patterns of sequences that will efficiently teach a given kind of knowledge. If successful, the result of this analysis is a theory of instruction for cognitive knowledge forms. Some examples will be given for several types of knowledge.

\section{Basic concepts}

Basic concepts are concepts that are best taught by examples, rather than definitions or synonyms (which are fact statements). Basic concept learning can be viewed as a multiple discrimination problem (Becker, 1986). Examples of concepts have to be discriminated from non-examples. The discriminations are between essential features positive examples (Sds symbolised as $\mathrm{S}+$ features), and essential features of negative examples (Sds symbolised as S- features), If positive examples are red (S+), negative examples are other colours (S- ). If you know an object is blue, you know it's not-red. Within positive examples and within negative examples, it is necessary to discriminate essential features from non-essential features. For example, if $\mathrm{S}+$ is red, non-essential features might include shape, size, texture, location, etc. (For more detail, see Becker, 1986).

To teach basic, single-dimension (or single-feature) concepts, such as right angle, smooth, or orange with examples requires a set of positive examples which all share the essential S+ features, and a set of negative examples, each of which do not share all S+ features. In initial teaching, Engelmann recommends that non-essential features be kept the same for the first 11 or so examples. A common setup, as illustrated in Figure 3, is used to focus learner attention on essential difference between positive and negative 
examples. In switching from positive to negative examples (or vice versa) keep everything the same except an essential feature (the minimum difference principle). Such pairs of examples clearly show concepts boundaries. If this is done consistently, the students learns that examples that are more different than the negative examples shown are also negative examples. In presenting positive examples for concepts with a range, sample the full range of possibilities with 3 or 4 examples to show the range of sameness (the sameness principle). The student will learn that other examples that fall within the range shown are also positive examples. Learner acquisition is then tested with 5 or 6 examples; and finally the irrelevant features are varied to expand the range of application.

These principles lead to an 11-step prescription for teaching any noncomparative, single-dimension basic concept. Consider the steps illustrated in Figure 3 to teach the concept flam before going on.

The concept taught in Figure 3 is, of course, over. Note that the setup does not change throughout the initial teaching examples. The sequence starts with two negative examples, then in going from example 2 to example 3 , and from example 5 to example 6, minimally different positives and negatives are used to focus attention on the S+ versus S- features. Examples 3 to 5 show the range of $\mathrm{S}+$. By starting with negatives, the learner is less likely to form a wrong hypothesis, since the minimally different positive will focus attention on the critical concept feature. Testing begins with example 6 and, finally, after example 11, the setup is varied to teach which features of examples are irrelevant and thereby extend the range of application of the concept being learned. This 11-step sequence should work efficiently for any non-comparative single-dimension concept, and thus provides a component for a theory of instruction.

Returning to Table 2, single-dimension comparative concepts come next. These can be taught by a 12-step sequence that follows that shown in Figure 3 except that it begins with a starting example. To illustrate, the starting example might be: "Look at this ruler in my hand." Then, the 11 steps used to teach non-comparatives are followed except that each new example is compared to the one before it. For example step 1 following the starting example might be: "It didn't get steeper" (it got less steep). Then step 2 might be: "It didn't get steeper" (example 2 is the same as 1). Step 3 might be: "It got sleeper" (example 3 is slightly steeper than 2), and so on. The same pattern of examples shown in Figure 3 is used, after a starting example, and each judgment is a comparison. A prescription for teaching basic comparative concepts is thus provided. For many single dimension concepts, such as steep, near, high, etc., where the meaning is relative to the context, the comparative form provides a clearer basis for initial instruction than the non-comparative form. 
The setup inwolves a mall ball held in the right hand and a mall writing board held in the left hand. The following examples are presented in order:

Eximplat

These are representations

of what the teacher does.

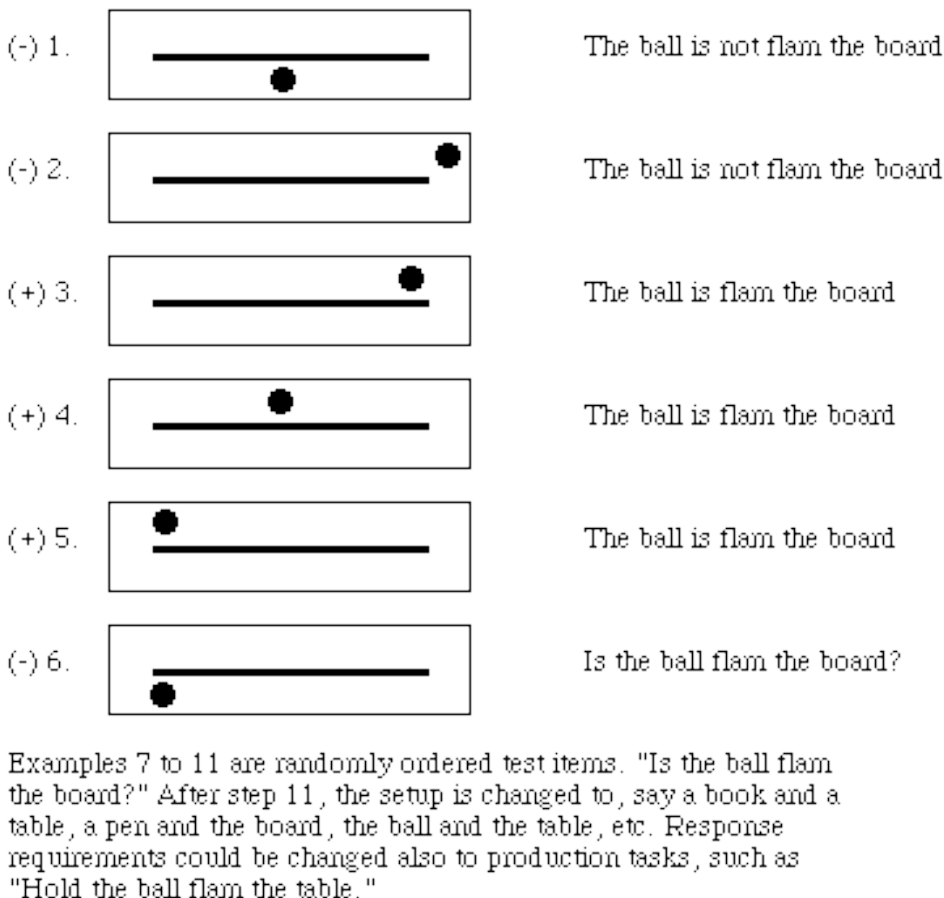

$(-) 1$

Teintous

The ball is not flam the boand

The ball is not flam the boand

The ball is flam the boand

The ball is flam the boand

The ball is flam the boand

Is the ball flam the boand?

Figure 3: Initial steps for teaching a single-dimension non-comparative concept.

The next type of concept in Engelmann's classification is nouns. A different strategy is required to teach noun concepts. Because nouns have many features, there are no precise minimum differences between examples and non-examples (eg, a horse and a cow, or a chair and couch). Also, because there are so many possible negative examples for noun concepts, it is safer for the designer to constrain negative examples to those known to be in the student's repertoire. Starting the sequence with positive examples will likely focus attention on the essential features more quickly. Since the names of the negatives have already been taught, they are used in identifying examples. The sequence might start with 3 or 4 positive examples and then negatives interspersed with positives. For 
example, in teaching truck, you might present a semitrailer, a van, and a pickup as positive examples; and then start testing ("What's this?") with a train (S ), a bus (S-), a flatbed truck (S+), a car (S-), a van (S+), etc.

As noted earlier, concepts can also be taught through fact statements. For example: "Above is another word for over"; "It's a vehicle if it can take you places"; "A chair is furniture that can hold one person in a sitting position and support the back." Whether concepts are taught by statements or examples depends on the concept and the learner's skills.

Because of space limitations, only key aspects of the strategies for teaching the major joining forms and complex forms listed in Table 2 will be presented. For more details, the reader is referred to Engelmann and Carnine (1982) or Becker (1986).

\section{Joining forms}

Joining forms join together two or more concepts. Logical rules (transformation rules) are found in the rules of grammar (eg, "More than one $\mathrm{X}$ are $\mathrm{Xs}$ "), the rules underlying mathematical systems (eg, "The third place from the right of a number tells how many 100s"), propositional systems, and other logical structures, such as class inclusion ("Boys and girls are children"). Only positive examples are needed to practice application of transformation rules. The student is taught to use the rule to complete examples and to explain what was done using the rule.

Fact statements name something and then say something about it ("Birds have feathers," "Matter will expand if you heat it," "The pencil is on that table"). Facts join concepts observed to go together. Principles are generalisable fact statements. They are taught by having the student use the principle to predict what will happen and then explain why it happened. Sequencing of examples for some symbolic facts follows a transformation sequence. For other facts, sequencing follows the steps for single-dimension concepts, except that two questions are used in the teacher wording (predict and explain) rather than one. For the principle "Ice melts if the temperature is above 32 degrees Fahrenheit" (with distilled water at sea level), the first few examples might go like this:

1. Ice is placed in a chamber that is 25 degrees. (Teacher) "It won't melt. How do I know? Because the temperature is not above 32 degrees."

2. Ice is placed in a chamber that is 32 degrees. (Teacher) "It won't melt. How do I know? Because the temperature is not above 32 degrees."

3. Ice is placed in a chamber that is 33 degrees. (Teacher) "It will melt. How do I know? Because the temperature is above 32 degrees." 
4. Ice is placed in a chamber that is 35 degrees. (Teacher) "Your turn. Will the ice melt? (Student) "Yes." (Teacher) "How do you know?" (Student) "Because the temperature is above 32 degrees."(4)

\section{Complex forms}

The strategy for teaching sets of related facts (fact systems) is derived from research showing that retention is better when both auditory and visual inputs of the same information are used, and is further improved when relationships are shown in visual-spatial displays. For these reasons, Engelmann organises related facts into fact charts (Engelmann, Davis \& Davis, 1982, 1983). Initial charts are built to cover broad areas of knowledge, which can then be augmented by further elaborations. Because much practice is required to master sets of facts, fact games (using fact charts with the words deleted) are used to motivate practice in small groups.

In cognitive theory, interrelated pieces of declarative knowledge (concepts, principles, patterned sequences of events, etc.) lead to structures called schemes (Anderson, 1990). These are much like Engelmann's fact systems. A primary difference is their source. Most cognitive psychologists try to learn about schemes mainly by trying to find out how they are organised in peoples' minds. Engelmann would logically analyse the knowledge to be taught for its structure, and when it involves facts, attempt to organise it into a fact system that can be directly taught through a visual and verbal presentation. Engelmann's practice of initially building broad structures to which more detailed knowledge can be added is in keeping with the cognitivists' descriptions of how new information is more readily learned when it can be fitted into a schema already in place (Anderson, 1990).

The design of problem-solving routines (algorithms) must vary for each problem set, but follows four general rules:

1. Specify the range of examples.

2. Make up a descriptive rule good for all examples.

3. Design a task that tests each component discrimination in the rule.

4. Construct a chain composed of the tasks that test the component skills in the routine.

The problem-solving routine in Figure 2 for "picturing a fraction" would first consider that fractions can be less than one, equal to one, or greater than one (the range of examples). Since fractions can be greater than one, the initial routine uses four wholes in setting up the format for student responding so that the setup does not cue how many wholes are in the answer. This format uses two descriptive rules which would be taught 
beforehand with transformation sequences (i.e., "The bottom number tells us how many parts in each whole," "The top number tells us how many parts we have." The tasks needed for the routine and an appropriate sequencing are illustrated in Figure 2.

In designing problem-solving routines, Engelmann plans for the transfer of component skills from one routine to another. This can provide a great savings in instructional time to accomplish a given objective. For example, nearly all of the steps in an addition routine (using an equation format and a counting strategy) transfer to an algebra addition format, a format for addition the fast way, and subtraction formats.

Cognitive psychologists' parallels to Engelmann's problem-solving routines can be found in Scandura's Structural Learning Theory (1983), and Landa's Algo-Heuristic Theory of Instruction (1983). As Reigeluth (1983) points out in his introduction to Landa's chapter in his book, "In spite of its cognitive orientation, Landa's theory is highly compatible with behaviourally oriented theories. The latter focus more on observable procedures (i.e., overt behaviours), whereas Landa focuses more on unobservable procedures, (ie, cognitive processes). Nevertheless, ... [they] require essentially similar methods of instruction" (p. 165).

There are many other important considerations in designing problem solving routines. For example, it is more efficient to teach all component concepts, rules, and procedures by themselves before teaching the full routine. In early formats, all steps in the routine should require overt responses. Without this requirement, there is no basis for precise corrections. Later teaching formats chunk steps to speed up the routines so they eventually are covertised. In Anderson's (1990) terms, the steps are complied and tied to procedures. From an instructional design viewpoint, this is one basis for describing the differences between the novice and the expert.

\section{Novice to Expert}

With the above background, it is not difficult for an operant psychologist to talk about novice to-expert differences in competence, such as differences between medical school students and specialists, or beginning readers and those with excellent comprehension. It is also not too difficult to describe the kinds of instruction that would be required to move the novice to the expert stage of functioning. The novice is more likely to be taught in small steps with direct instruction in order to build up a base of concepts and principles (the declarative knowledge base) needed for later problem solving. The novice is more likely to be taught with an attention to consequences (praise for effort and corrections of errors). As expertise develops, a number of systematic changes occur. Some of the changes that go on in progressing from a novice to an expert are: 


\section{Developing automaticity of basics}

The expert has the component skills needed for solving problems automatically available. This allows a focus on critical aspects of the problem. To the operant psychologist, automaticity can been seen as the result of the frequent repetition of a chain of behaviour. The control of each component in the chain by external Sds drops out and is replaced, presumably, by response-produced stimuli (the internal stimuli produced by actions). Instead of typing a word one letter at a time by referring to a keyboard chart, the word is typed as a unit. Instead of sounding out each letter in a word phonetically, the whole word (or phrase) is read. New functional units of behaviour are formed where all the steps are fused and seem to occur automatically. In reading, a major goal should be to make decoding automatic through practice so that the learner can focus attention on comprehension of what is being read (LaBerge \& Samuels, 1974).

\section{Compilation and Proceduralisation}

Steps in routines become chunked (compilation) and relevant declarative knowledge (ie, concepts and principles) are tied to problem-solving procedures (Anderson, 1990). As noted earlier, in designing problemsolving routines, Engelmann first keeps all steps overt so errors can be corrected and feedback given. Concepts, rules, and principles are made explicit in the routines (and taught separately before being use in a routine). Then overt steps in the routines are gradually combined through changes in formats until students perform on their own. Steps fuse together and become internalised as external prompts are faded. In Anderson's model of the expert, declarative knowledge is tied to procedural knowledge where it is explicitly needed. In Engelmann's scheme, concepts and rules become part of problem-solving routines through direct program design.

\section{Conclusion}

When procedures needed to operationalise cognitive models are made explicit, as they must be for instruction, operant psychologists have no trouble accepting them or fitting them in with their basic principles. Operant psychologist and cognitive psychologists are both often talking about the same "elephant" from different perspectives. Because there is still much to be learned about instructional models for higher-order cognitive processes, it might just be that the cognitivists could benefit from a closer examination of where operant psychologists are, and where they are going, and vice-versa. 


\section{Reference Notes}

1. This is a modified version of a paper presented at the First Australasian Regional Conference of The National Society of Performance and Instruction sponsored by the Sydney Chapter August 18th-19th, 1990. Copyrighted 1990 by the author. All rights reserved.

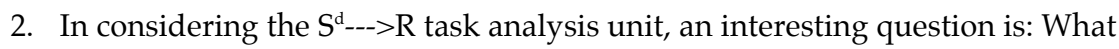
controls the size of the response unit used in a task analysis? I believe it is function of how big a response sequence is under control of a single Sd (eg, verbal cue). For example, while one could break hand washing for a child with limited intellectual functioning into 18 steps like: "Walk to the bathroom," "Push open the door marked women," 'Walk to the sink," etc., six steps might be enough for some children, and one for others ("Go to the bathroom and wash your hands"). This is one reason why pretesting is so critical in efficient program design. Some designers have felt that because a task can be broken into smaller parts, that it should be. Decisions on appropriate units require empirical investigation. All of this is, of course, related to the chunking of behaviour with repetition, automaticity, progressions from novice to expert, and the behavioural concept of a functional response class.

Glaser (1987) expresses a parallel set of ideas from a cognitive point of view focusing on rules and principles rather than procedures: "The knowledge underlying problem-solving skill is represented as a set of if-then goal-oriented production rules. The tutor monitors whether or not a student has carried out each rule correctly, and it responds to any errors or missing rules. The learning theory involved assumes a knowledge compilation process, in which, as experience is acquired in a domain, sequences of rules collapse into larger macro rules. This enables the tutor to adjust the grain size of instruction as learning proceeds" (Glaser, 1987, p.xv).

3. Most cognitive psychologist approach problem solving by analysing what students (or experts) do in solving problems, and by exploring the underlying networks of facts, concepts, and procedures needed to solve problems in various domains. The focus is on what goes on in the mind, not on what should go on based an analysis of what is to be taught. Glaser's (1987) overview in Volume 3 of Advances in Instructional Psychology provides excellent suggestions for instruction derived from cognitive research that I find mostly compatible with the view of operant psychology presented here.

4. Principles and rules are at the heart of cognitive psychology (see Glaser, 1987; Reigeluth, 1983). And yet, as Engelmann and Carnine's formats for teaching rules and principles (and their demonstrated effectiveness) illustrate, these cognitive structures can be built from simpler behavioural processes. In a similar vein, the capabilities that Skinner (1957) called self-management behaviours and which cognitive psychologists call metacognitive processes also fit into this context. Self-management behaviours, in part, involve rulegoverned behaviour and making plans (sets of steps to follow). In these activities, verbal chains of behaviour (in the head or on paper) are used to control sequences of action, including problem-solving activities, study behaviour, etc. 


\section{References}

Anderson, J. R. (1990). Cognitive Psychology and its Implications. New York: Freeman.

Becker, W. C. (1986). Applied Psychology for Teachers -A Behavioral Cognitive Approach. New York: Macmillan. (Originally published by Science Research Associates.)

Brophy, J. (1984). Designing curriculum and instruction. Contemporary Psychology, 29, 622-24.

Bruner, J. S. (1966). Toward a Theory of Instruction. Cambridge, MA: Belnap Press.

Chomsky, N. (1959). Verbal Behavior, by B. F. Skinner. Language, 35, 26-58.

Engelmann, S., \& Carnine, D. W. (1982). Theory of Instruction: Principles and Applications. New York: Irvington. (Being republished in early 1991 by the Association for Direct Instruction, PO Box 10252, Eugene, Or.)

Engelmann, S., Davis, K. \& Davis, G. (1981). Your World of Facts, Level 1. Chicago: Science Research Associates.

Engelmann, S., Davis, K. \& Davis, G. (1982). Your World of Facts, Level 2. Chicago: Science Research Associates.

Gagne, R. M. (1965, 1970, 1977). The Conditions of Learning. New York: Holt, Rinehart and Winston.

Gagne, R. M. (1968). Learning hierarchies. Educational Psychologist, 6, 1-9.

Gagne, R. M. \& Briggs, L. J. (1974,1979). Principles of Instructional Design. New York: Holt, Rinehart and Winston.

Glaser, R. (1987). In R. Glaser (Ed.), Advances in Instructional Psychology (Vol. 3). Hillsdale, NJ: Lawrence Erlbaum Assoc.

Goldiamond, I. \& Dyrud, J. E. (1966). Reading as operant behavior. In J. Money \& G. Shiffman (Eds.), The Disabled Reader, 93-115. Baltimore: John Hopkins.

Keller, F. S. (1968). "Good-bye teacher... " Journal of Applied Behavior Analysis, 1. 79-89.

Landa, L. N. (1983). The algo-heuristic theory of instruction. In C. M. Reigeluth (Ed.), Instructional-Design Theories and Model: An Overview of their Current Status. Hillsdale, NJ: Lawrence Erlbaum Assoc., 163-180.

LaBerge, D. \& Samuels, S. J. (1974). Toward a theory of automatic information processing in reading. Cognitive Psychology, 6, 293-323.

Lee, V. L. (1988). Beyond Behaviorism. Hillsdale, NJ: Lawrence Erlbaum Assoc.

MacCorquodale, K. (1969). B. F. Skinner's Verbal Behavior: A retrospective appreciation. Journal of the Experimental Analysis of Behavior, 12, 831-841.

Newell, A., Shaw, J. C. \& Simon, H. (1957). Preliminary Description of a General Problem Solving Program-I (GPS-I). Report CIP Working Paper 7, Carnegie Institute of Technology, Pittsburgh, Pa. 
Reigeluth, C. M. (1983). Instructional-Design Theories and Models: An Overview of their Current Status. Hillsdale, NJ: Lawrence Erlbaum Assoc.

Scandura, J. M. (1983). Instructional strategies based on structural learning theory. In C. M. Reigeluth (Ed.), Instructional-Design Theories and Models: An Overview of their Current Status. Hillsdale, NJ: Lawrence Erlbaum Assoc., 213-246.

Skinner, B. F. (1953). Science and Human Behavior. New York: Macmillan.

Skinner, B. F. (1957). Verbal Behavior. New York: Appleton-Century-Crofts.

Skinner B. F. (1968). The Technology of Teaching. New York: AppletonCentury-Crofts.

Skinner, B. F. (1977). Why I not a cognitive psychologist. Behaviorism, 5, 110.

Watson J. (1930). Behaviorism. New York: Norton.

Author: Dr. Becker got his PhD in Psychology at Stanford in 1955. He worked 15 years at the University of Illinois, before moving to Oregon. His early research focused on how parent behaviour influenced personality development in children. He then moved into schools where his research has been largely with younger children, first in showing teachers how to deal with behaviour problems and then with better instruction. From 1968 to 1978, he worked with Siegfried Engelmann and Doug Carnine within project Follow Through, a federal program for economically disadvantaged 5 to 9 year olds. It was an attempt to Follow Through on gains possibly made in Head Start programs. This instructional model was called the Direct Instruction Model. The model was most effective of nine comparison models in bringing disadvantaged children up to national norms in reading, mathematics, language, and spelling. During the past eight years he has been teaching a graduate course on Instructional Psychology.

Please cite as: Becker, W. C. (1991). Toward an integration of behavioural and cognitive psychologies through instructional technology. Australian Journal of Educational Technology, 7(1), 1-18. http:/ / www.ascilite.org.au/ajet/ ajet7/becker.html 